\title{
THE CONCEPT OF SUSTAINABILITY FROM AN ARCHITECTUIRAL VIEW IN LIBYA
}

\author{
Dr. Mariam M Shibub \\ Architecture Department and Urban Planning, Faculty of Engineering, Tripoli University \\ dr.mariamshibub@gmail.com
}

\begin{abstract}
Libya is considered a virgin land for sustained development, and with its small population, the country's productivity and consumption are still insignificant. Libya's architectural heritage, which remains untainted by the pollution problems which plague more industrial countries. The most important problems facing the country are desertification and limited water supply. The failure of the Libyan State to enact laws to address these problems has contributed to their increase.

This article deals with the concept of sustainability and its relation to the architecture science and its intellectual and cultural dimensions. In addition, the local efforts in Libya that aim to set up a local plan for coping with the international efforts and the resulting work rules regarding this concern. This article arrived to some recommendation that the Libyan authorities may take into consideration of developing educational curricula especially in the field of architectural engineering and urban planning so as to cope with the theories and principles of sustainable architecture.
\end{abstract}

Keywords: The Environmental System, Sustainability, the Work Rules.

\section{Introduction}

"The most widely accepted definition of sustainable development appeared in 1987. Since then, sustainability means meeting the needs of the present without compromising the capacity of future generations to satisfy their own needs." (Pascual L.; Francisco,S. p. 1156. 2015)

The effects of the fluctuation in temperature impose a great challenge for architects and calls for a new comprehensive vision and an international style of thinking that deals with the human issue everywhere as one unit. The decision to establish an industrial zone or a settlement apart from the agricultural or green land will not only affect the surrounding people but also various places across the world. Its impact will increase with time and population growth. The decision of the architect or the planner has a wide range of impacts, and he/she is therefore called to return to nature and to respect natural sustainability factors, establishing green buildings and cities as a response to the fears emanating from the fluctuation in temperature and international environmental issues. They are the same callings of today that place the sustainability factor as a crucial factor among the planning objectives, development, 
and design. Then they, whether at the general or individual level, will be based on moral aspects that understand international human issues and consider the impacts of continuity or sustainability as an Influential factor in architectural work (wong,Y \& Siu, M. 2018).

The examiners of the development of previous design strategies and theories will realize that they have been affected by frequent issues such as technological changes and developments in building materials and scientific discoveries, construction theories, the economic vision etc. All the prevailing issues in the eighties and nineties that established concepts in design were based on strategies, such as: energy, design, use of solar energy in design, reduced energy, etc (Pollington, C \& Sebestyen, G. 2007).

Further, the vision to design using the advanced production of building materials and construction systems from the sixties and seventies until this era were obvious. Until recently, the subject of environmental architecture has prevailed, with architectural design being evaluated according to its response to the environment, in favor of protecting humans from the elements. Then, the subject of the side-effects emerged and in a study of the expected impacts of the project after execution. Hence, the design criteria became focused on the impact of human activity upon the surrounding, as it was not expected that human activity would have long-term environmental effects (Brebbia, C.A. 2012).

\section{Problem Statement}

The environmental, cultural and social changes and problems that may have taken place in the Arab societies in general and in Libya in particular are reflected in one way or another in architecture. The architects tried to respond to environmental changes and requirements to solve all the problems that may have an impact on the comfort of the user within the architectural spaces. Therefore, the researcher, sheds light on the concept of sustainability and attempt to help to increase understanding of how its characteristics are reflected in aspects of the field of architecture. This is vital because of its impact on the progress of urban and architectural development for cities and its suitability and adaptation to environmental changes to create a sustainable and environmentally friendly architectural environment that meets all the needs of the individual and society. Environmental problems following that affected many human activities and caused the field of architectural design, as one of the factors contributing to the high consumption of energy, to face a difficult challenge.

\section{Methodology}

In order to understand the main concept of this study, (which is sustainability,) and its relationship with architecture, the researcher used the inductive methodology to focus on the following steps:

1. General overview on human activity and its direction through the sustainability concept.

2. Defining the benefits of applying the concept of sustainability.

3. Describing the intellectual and cultural dimensions. 
4. Focusing on international and local efforts in the subject of the sustainability.

5. Offering recommendations that should be submitted to the Libyan architects, engineers and authorities.

\section{Human Activity}

The more increase in human activities, the greater the human impact on nature will be until humans become victims of their own impact. With the emergence of environmental pollution and its negative effects on humans, there is a need for nature protection and preservation to protect humans from their selfish deeds that override their own interest without comprehensive vision of the interests of others (Govorushko, S. 2011). "Nowadays, due to a growing understanding of human interaction with nature, it is widely accepted by the scientific community that consuming energy from non-renewable sources has caused serious environmental damage" (Marques,B and Loureiro, C. p. 223, 2013).

Hence, the human is looking for sustained interest with the need for viewing human activity and its direction through the sustainability concept. One must seriously consider the human risk to nature, or what is called internal risk, by confronting the threat of humans to nature. Therefore, one must consider what nature could do for us and, what we can do for nature-from risks and threats by nature to humans, to risks and threats of human activity to nature, or from natural risks to artificial risks. Humans look to sustainable architecture as guide for better life and change their activates according to this development. (Raghab, A and Elhimy,h. 2016).

Thinking about the artificial risk resulting from human activity is summarized in three points according to several intellectuals like Charles Jencks (2007) in his critical book of modernism architecture indicates that human civilization will not achieve substantial progress towards solving the problems facing humanity if raising the standard of living is always a planning priority. The prevailing doctrine and the adopted styles of development are not realistic and are connected more to the economic situation. This vision will increase the occurrence of problems. The greenhouses that were adopted as means of increasing food production and their resulting problems, in addition to the increase of industrial activity aiming to supply goods for markets to achieve luxury and a better living standard, have resulted in the increase and expansion of the hole in the ozone layer. This is the best example illustrating the negative effect of human civilization when its priority is placed primarily on economic interests.

The human has created the danger that is attacking him/her. For the first time in history, the image is inverted on the stage; the actors become the proscenium, and nature is the actor on the proscenium (Jencks, C. 2002). The sources of this danger were illustrated in the following three factors:

- Increase in population density.

- Depletion of nature for improving the standard of living. 
- Depletion of natural resources due to industrial techniques and their harmful effects on nature.

The analysis of these issues involves controlling the above three factors either by decreasing the population density or by using consumption living styles that do not negatively affect nature, or by controlling the industrial technological production and stopping the activities that are harmful to nature. Sullivan \& Benet, (1994) transformed this relationship into the following equation:

The environmental impact of a population group= Population $\mathrm{x}$ consumption $\mathrm{x}$ Technology.

This formula expresses an important result and imposes limits on the continuous increase and growth of the human race and limits its environmental impact which should be connected to the level tolerated by the international environmental system. However, this is not astatic system; the environmental impact of humans changes over time (historically increasing but neither the population, consumption nor the technology are constants and impacts can potentially decrease as well as increase) (Radford, A. Williamson, T. and Bennetts H. 2004, p. 4).

The world environmental systems, besides population and technical consumption, are not constant; all of them are variable systems throughout time. Historically, they fluctuate between a continuous decrease and increase. It is not logical to accept the suitable international environmental features without the existence of humans in an unsuitable environment for human life, but the ambitions of some opportunists to entirely control the world may lead to the destruction of the world and begin a new civilization with thoughts different from the present (Harfe, F. 1998).

People may have a destiny of a luxurious and exciting life, but it is a short life in a green quiet environment. Those who are lacking spiritual ambition prefer enjoying the sunrise and do not think about who inherit the earth (Edwards, B 2001). Most people hope to avoid horrors not only for themselves but also for their sons and decedents. Plants and agriculture stand to decrease an important part of these artificial horrors and risks. Accordingly, sustainability emerged as a concept involving several cultural, social, political, and economic meanings or what is commonly known in Europe and Australia as (E.S.D). These three letters are the abbreviation of several words and terms: "E" stands for Ecology and Economy, "S" for Sociocultural and Sustainability, and "D" for Development and Design (Antony, F\& Williamson T\& Bennetts, H 2003).

\section{The Concept of Sustainable Architecture}

This study illustrates the concept of sustainable Architecture, and connects human life to the extent of tolerance of environmental systems of nature that leads us to a comprehensive term connecting social, cultural, environmental life and development. 
People may inquire: what does sustainability mean to architectural engineering? The right question might be: what does architectural engineering mean to the sustainability? The first question presents a weak vision of sustainability. In other words, it provides an implicit hypothesis of sustainability that has serious results on our recent methods to obtain buildings. The first question means that these methods are suitable and form a crucial aspect when viewing sustainability, while the second question recognizes sustainability as source of concern for all attempts that necessitates re-viewing and reformulation of social disposals and behavior in all fields (Antony, R, Williamson,T \& Bennetts H 2003).

Sustainability is defined in the dictionary as the continuity and preservation of resources. It is composed of "sustain", which means constant, and "able" by the meaning of capable. The combination of these word components means capable of being sustained, relating to, or being a method of harvesting or using a resource so that the resource is not depleted or permanently damaged as in sustainable agriculture, relating to a lifestyle involving the use of sustainable methods: sustainable society (Aslani, R (2001). "Sustainability, therefore necessitates a contemporary way of thinking, it requires the scrutiny of traditional values and economic measures and definition or perhaps a redefinition of quality of life" (Sassi, P. 2006. P,4). The concept of sustainability stands at the center of efforts to develop an architecture capable of meeting the challenges of the future (Brodhag, C., \& Taliere, S. 2006). Therefore, "the sustainable architecture makes stimulating and solidly argued contribution that of an architect engineer who is convinced of the importance of the ecological challenge and who applies his knowledge in service of the cause" (Revedin, J. Hélène, M. Chavannes,C. Revedin, J. 2013, p. 146).

"Sustainable architecture challenges new and ingenious architectural design at various levels. Examples are the following. (1) Minimizing the negative environmental impact of buildings by enhancing efficiency and moderating the use of materials, energy and development space. (2) Developing measures to relate form and adapt the design to the site, the region and the climate. (3) Establishing a harmonious, long lasting relationship between the inhabitants and their surroundings by addressing the essence of good form-giving”. (Keitsch, M, P. 141, 2012).

\section{The Intellectual and Cultural Dimensions}

There were three features of thinking: which is simplicity or reductionism, modern living and realist philosophy, that affect the method by which the European deals with problems that face him and the method of taking decisions including the decision of building design. This dual thinking illustrates the relationship between the body and the mind, substance and soul, reason and emotion. Body, substance, and reason refer to the world that is extending beyond selfawareness, a world in which phenomena are viewed through the interaction between principles and values. This division separates between expected, oriented, and regular events and unknown, variable, and fluctuating events (Paul J, 2006). 
The mind-body dualism practically places the human being as a part of nature and places the human individual soul as separate from everything outside the soul and it is responsible for setting the code of conduct that is appropriate to it. On the other hand, the mind, the spirit, and emotions together with the intellect, totally adopt the expertise and sensation. So, feelings are disregarded and morals are not-existent in this case (Bauman, 1995).

The second feature is modern living. All difficult big entities involve smaller and easier essential entities. Hence, man discovered the method of acquiring knowledge: thinking of the topics that he encountered through studying the situation, and then breaking the problem into smaller units. Then man followed the process of trying to understand the simple units of the compound problem and then trying to re-assemble it. When we deal with the big or complete problem and its analysis by considering its primary elements, this will help us understand and sort out the big problem (Balaram, S. 2011).

This is clear in the realist philosophy that believes in the infinite capability of human reason to control everything in order to utilize the potential of nature and to understand and manage everything within it in his favor (Brez, Gemz. 1983). An alternative vision emerged from a different philosophical view that presents each of the traditional scientific examples and a various point of view that controls the proportionality between acts and results. The ecology of the world is a science studying the relationship between living organisms and their environment or the relationship between a group of people and their environment. In this respect, the world is composed of biotic and non-biotic elements as complementary elements for the environmental system. In ecology, the philosophical vision exceeds the limits of the analytical and experimental world for the direct experiments and enters in the unseen world in which the substantial understanding of the environment is unknown (Harrison, A. 2013).

Ecology illustrates perspectives and examples about the systems that work naturally to achieve sustainability and these systems are subject to human interference. Actually, the environmental systems work naturally and they are mostly sufficient to set an example that provides us with a scientific vision of sustainability (Barr, S., Gilg, A. 2006). The absence of continuity in natural systems generally indicates two issues. The demands imposed on resources are critically increasing over the tolerated limits of the natural system. The amendments and changes exceed the natural facilities. It also provides us with a valuable indicator of the logically probable, ambiguous, and fearing risk. This topic illustrates the environmental frames and opinions that were unable to reach the ideal balance between human selections issues and human interferences. While post-modern aspect will continue as a dominating framework over the practice of architects' professions that gives a list of political, legislative context of design standards, and other professional practices. The post-modern scientists, theorists, and critics indicates the heavy predicament facing us as we are searching for the suitable methods to sort out the problems (Alvarez, S.P.; Lee, K.; etc. 2016).

Science has become one of the most effective fundamental methods of understanding the world. The confidence that is based on the scientific methodologies has led to new 
technologies that contribute to health and financial status for many people. Nevertheless, it has also brought the discovery of destructive weapons and the excessive use of limited resources. Assuming that the world's resources are open for human consumption and are there to fulfill all human purposes, has led to the destruction and pollution of the most of world's natural environment in addition to complete extinction of species. In addition, sustainability is a relevant discussion in forming the opinions of postmodern culture (Devara, D. 2014).

The sustainability idea is derived from science. At the same time, it imposes restrictions on science that is used as moral solution for human problems, according to priorities acquires its validity from the distinction of priorities. It represents a crucial aspect of modernization of traditions and ensures cultural diversity. Some authors consider this to support the concept of sustainability. "This observers requires that architecture be understood not in the aesthetic terms of high culture but in the social and material context of every day life" (Steven, A. 2011 p. 197).

\section{The International Effort}

In 1987, the International Committee for Environment and Development announced their determination for sustainable or continuous growth for the common future of humanity (known as the report of Brund-land) that states: humanity is capable of making development continuous or sustainable to ensure its recent needs without affecting the right of the future generations regarding the provision of their own needs.

This continuous growth should adopt steps to direct the technological development, and an institutional change looking towards the future in addition to meeting the recent needs (WCED, 1990). This definition involves two crucial elements of the continuous growth:

First: to accept the concept of needs such as food, clothes, and housing and all the necessary needs for human life.

Second: to accept the concept of connecting the resources of the required technology, to provide the recent and future needs of the social institutions, to the environments tolerance ability.

This involves all the local and international considerations and interests that have political and economic dimensions relevant to the issues of controlling the resources and relates to the gap between developed countries and developing countries. Accordingly, the idea of continuous and sustainable growth, free from the future results of open mono-growth that ensure the improvement of human life quality, is achieved within the limits of the tolerance of environmental effects on nature (James, V. 2018).

The scheme of considering sustainability as an essential and integral feature of all development processes after the declaration. Brund Land Committee was reflected in the international notices, agreements, and other work plans. Hence, the Earth Summit that was 
convened on June 1992 in Rio de Janeiro, Brazil was a prominent event in the sustainability movement not only for meeting of an unprecedented number of countries, organizations, and citizens from all over the world, but for the first time the developed and developing countries reach an agreement on some relevant difficult issues of the environment and rural development. The summit concluded with the Rio Declaration concerning environment and development involving 27 principles regarding the achievement of international sustainability. This involves primarily the principle that underlines the great concerns that threaten humanity and oblige humans to strongly consider sustainable growth. All of them have the right to a healthy life on par with nature potentials (Nath, B \& Hens, L. 2006).

Several agreements and important international documents released after the Earth Summit such as the Agenda of the $21^{\text {st }}$ session of the General Assembly (United Nations, 1992), United Nations Framework Convention on Climate Change (UNFCCC, 1992), The Convention on Biological Diversity (CBD), (UN, 1992), and the United Nations Convention to Combat Desertification (UNED, 1992). All these four agreements have a relationship with the sustainable architectural engineering aiming to stop the environmental harm to our planet, achieving continuous or sustainable growth all over the earth, and moving from the discussion of theoretical sustainability to setting up a work plan in the form of proposals guiding the growth of residential groups all over the world to apply certain practical procedures concentrated on eight principal objectives that targeted the improvement of environmental, economic and social conditions of human settlements and general environments which are:

1. Providing shelter or sufficient housing.

2. Improving the management of urban settlements.

3. Planning and managing the land use on par with sustainability.

4. Providing environmentally proper infrastructures.

5. Shifting to the alternative and renewable energy.

6. Determining the source and systems of sustainable transport.

7. Enabling countries of disaster concerned with planning to recover from natural disasters.

8. Promotion of activities and industry of sustainable construction working and development of human resources (UNED, 1992) .

The purposes of The United Nations Framework Convention on Climate Change (UNFCCC, 1992) is to slow down or stop the expected changes of thermal phenomenon that affect the climate that is relevant directly or indirectly to human activity, whereas the building process contributes greatly in the production of carbon dioxide and other radiations that are responsible for these thermal changes. This convention had a long-term impact upon the design of buildings and changes of houses design within the limits of architectural engineering. 


\section{At the Local Level}

In order to further the fruitful efforts exerted to combat desertification, expand the agricultural area, and protect the natural resources, the environment subject took executive administrative forms in the eighties. In 1982, the Libyan cabinet issued a resolution to set up maintenance and operation authorities, lately known as environment protection authorities, in municipalities. In 1992, the cabinet released a resolution to establish civil committees to protect the environment from pollution. In 1993, the cabinet issued a resolution to set up a general administration of environment. Then the people's general congress released a decision to form a ministry of environment that lately become the Public Authority of Environment, in addition to the establishment of a research center for building materials. However, the subject of architectural sustainability was not directly dealt with until in 2007, a symposium on sustainable architecture was held under the supervision of Urban Planning Authority. Further, the project of sustainable development in the region of Al Jabal Al Akhdar was founded as an aspect of this concept that has important impacts upon third generation planning. This subject still requires further interest as it did not take its correct form yet.

Libya is considered as a virgin land for sustained development. It is replete with various interface, natural, and biological balance without serious pollution problems. Nevertheless, the most important problem facing the country is the low limit of natural water resources and the desertification problem in addition to the non-activation of laws and regulations issued in this regard.

\section{The Work Rule}

The conference of the International Union of Architects convened in June 1993 in Chicago, USA under the slogan of environmental and social sustainability. The conference concluded the following:

"We commit ourselves,

As members of the world's architectural and building-design professions, individually and through our professional organizations, to:

- Place environmental and social sustainability at the core of our practices and professional responsibilities;

- Develop and continually improve practices, procedures, products, curricula, services, and standards that will enable the implementation of sustainable design;

- Educate our fellow professionals, the building industry, clients, students, and the general public about the critical importance and substantial opportunities of sustainable design.

- Establish policies, regulations, and practices in government and business that ensure sustainable design becomes normal practice 
- Bring all existing and future elements of the built environment - in their design, production, use, and eventual reuse - up to sustainable design standards" (Antony, F\& Williamson T \& Bennetts, H. 2003. P. 6).

It is obvious that this declaration or commitment is associated with the concepts of architectural engineering and sustainable development. The sustainable design of many types of buildings began from huts in Africa to buildings and technological offices in the United States and Europe. The African huts are considered a sustainable design for they are completely built from degradable materials that do not represent a source of pollution that causes biological or environmental damages. Huts also utilize a very little amount of international resources to build as compared to western buildings. The office building is an example of sustainable design if it is significantly abiding by the least consumption of energy for heating, cooling and lighting compared to the other. Both of them illustrate the values that came to associate building with sustainability (Bonsdorff, 1993). Suzan Maxman, the head of the American Institute and other architects, the head of the international union of architects maintained that the sustainable architectural engineering is not a medical prescription but it is a vision and position regarding architecture (Maxman, 2000). According to this data, the following questions arise: how should other architects and designers respond to this data? How should they behave as designers to make decisions that concern the daily practice of the profession? There are lists and rules for auditing and revising the design recommended in many books and websites. Some green designers like William McDonough (2000) have set the principles believed to support the sustainable design represented in the nine points known as the Hannover's Principles for Sustainable Design that were proposed by McDonough when he was assigned to develop the principles of sustainable design of the Hanover's international Fairground in 2000 which are:

1. Insist on rights of humanity and nature to co-exist in a healthy, supportive, diverse and sustainable condition.

2. Recognize interdependence. The elements of human design interact with and depend upon the natural world, with broad and diverse implications at every scale. Expand design considerations to recognizing even distant effects.

3. Respect relationships between spirit and matter. Consider all aspects of human settlement Including community, dwelling, industry and trade in terms of existing and evolving connections between spiritual and material consciousness.

4. Accept responsibility for the consequences of design decisions upon human well-being, the viability of natural systems and their right to co-exist.

5. Create safe objects of long-term value. Do not burden future generations with requirements for maintenance or vigilant administration of potential danger due to the careless creation of products, processes or standards.

6. Eliminate the concept of waste. Evaluate and optimize the full life cycle of products and processes, to approach the state of natural systems, in which there is no waste. 
7. Rely on natural energy flows. Human designs should, like the living world, derive their creative forces from perpetual solar income. Incorporate this energy efficiently and safely for responsible use.

8. Understand the limitations of design. No human creation lasts forever and design does not solve all problems. Those who create and plan should practice humility in the face of nature. Treat nature as a model and mentor, not as an inconvenience to be evaded or controlled.

9. Seek constant improvement by sharing of knowledge. Encourage direct and open communication between colleagues, patrons, manufacturers and users to link long-term sustainable considerations with ethical responsibility, and re-establish the integral relationship between natural processes and human activity (McDonough, W. 2000).

These principles aim to involve the stakeholders in the design process. These stakes are human and natural (Principle 1) so as not to burden the future generations with the requirements of maintenance (Principle 5), the method of achieving purposes by means of renewable solar or natural energy which works efficiently and safely for the proper use (Principle 7). The vision towards involvement of others in the design by encouraging direct and open communication between colleagues, patrons, manufacturers and users (Principle 9).

The vision towards sustainable architectural engineering necessitates the reconsideration of the conceptualized architectural engineering in terms of beliefs, purposes, operations and guidance that requires publicity and promotion. To achieve a more sustainable architectural engineering, it should be based on a coherent understanding of moral attitudes, objectives, environmental and administrative systems, and the limits of the adopted policies to guide public and individual works. In this regard, there are several spontaneous questions such as:

- How can we clarify the conceptualized architecture sustainability?

- When adopting the moral issue as an essential rule of work, what are the new professional ethics?

- Who are the stakeholders or partners?

- How do the indicators of understanding differ from a comprehensive behavior of systems?

- How can we achieve sustainable architectural engineering?

When dealing with these questions, we should consider sustainable architectural engineering as a producer of properties and standards of design, development, and production of buildings, material and styles of building in line with natural contexts that also takes into consideration the consequences of change of concepts and differences of interests.

In 1989, in Australia, the concept of sustainability developed political trends that helped to solve the socio-political disputes regarding the competition between environmental interests and developmental interests. This process begun with an initiative under the leadership of the Prime Minister Bob Hawke at that time, whereas in this same year an initiative or a 
declaration in form of a statement about environment was issued under the title of Our People, Our Country, Our Future. This initiative resulted in launching a national strategy for the Ecologically Sustainable Development in 1992 that was called E.S.D., which presented principles. The Preventive principle: there should be no postponement of putting limits on environment deterioration due to lack of integral scientific fact. Justice and the Right of Future Generation: Protection of natural resources for the benefit of future generations (Janet, M \& Thomas \& Scott, J \& Callan. 2013).

Economic and Environmental Valuation: the actual cost of the environmental impacts should be analyzed and distributed between the market economic factors. This strategy has been approved by the Australian national and local government and came into effect in many fields such as in 1996 when setting the project of general environmental policy of the Central Sydney Development Control Plan. There was a commitment to these principles of ecologically sustainable development in an integrated manner at all levels from the planning and development level to the urban design level as this experiment was applied for similar aspects in some other countries (Evans, M. 2000).

Many national and international organizations emerged in this regard with different names such as in Italy, the Rome Club, and Friends of the Earth International in Europe, America, and Australia. The Forest Stewardship Council (FSC) was founded in 1993 as an international system of protection of forests and natural reserves. Accordingly, many unknown terms and tools came out: for example: culture clamps wash, green wash, eco gadgets, and wind catcher (Forest Steward Ship Council. 1993). Design is a friend of the nature and green buildings are friends of the earth. Sometimes these nomenclatures are used for rural materials and sometimes for technological tools. These decomposable materials and the technological tools may present successful contributions in the subject of urban sustainability and they are important elements due to their properties that match the principles of sustainability.

\section{Conclusion}

- The decision of the architect or the planner has a wide range of impacts, and he/she is therefore called to return to nature and to respect natural sustainability factors, establishing green buildings and cities as a response to the fears emanating from the fluctuation in temperature and international environmental issues.

- The more increase in human activities, the greater the human impact on nature will be until humans become victims of their own impact. Hence, the human should look for sustained interest with the need for viewing human activity and its direction through the sustainability concept.

- The concept of sustainability was associated with architectural engineering due to the importance of planning and design and their role in setting and developing the styles of living and consumption. 
- sustainable Architecture and it's connecting to human's life and dealing ways with environmental systems of nature that leads us to a comprehensive term connecting social, cultural, environmental life and development.

- The international and local interests that have political and economic dimensions that relevant to the issues of controlling the resources and minimizing the gap between developed countries and developing countries. This cooperation will have a long-term impact on the design of buildings and changes in houses design within the limits of architectural engineering.

- The vision towards sustainable architectural engineering necessitates the reconsideration of the conceptualized architectural engineering in terms of beliefs, purposes, operations and guidance that requires publicity and promotion.

- Justice and the Right of Future Generation through protection of natural resources for the benefit of future generations

The international descending image of poverty, non-respect of environment, environmental degradation, garbage, and limited resources, and irresponsible human activities have resulted in an unbalanced relationship between north and south, east and west. This relationship between poverty, inequality and environmental degradation have formed a main subject that must be dealt with. On one hand, we need increased sustainable development for those in poverty and need. On the other hand, those who live in abundance must learn to limit their wastefulness and change to sustainable methods.

\section{Recommendations}

Libya needs several measures and programs, particularly in the fields of alternative energy, policies of production and consumption, protection of environment and forests, preserving coastal, mountainous and desert natural potential, and diversification of limiting natural reserves in order to cope with international requirements. Libya also needs sustainable development and needs to control the rapid development witnessed by all its regions and territories so as to ensure the sustainability of its resources, its natural status, and the right of the its future generations and to contribute to preserving the earth as internationally required.

Libya has monumental potential because of fertile, heritage, natural, environmental, and intellectual resources. These empower Libya to lead and to build a culture of involvement for all people and to accept social, political, economic, and cultural diversity within the society. It is necessary to develop educational curricula especially in the field of architectural engineering and urban planning so as to cope with the theories and principles of sustainable architecture. In order to achieve this, Libya needs a concerted effort that includes: distribution of missions, expansion of seminars and conferences by competent authorities, and a strategy regarding sustainability for universities, faculties, and scientific research centers under supervision of the General Planning Council. 


\section{References}

- Antony, F; Williamson T; Bennetts, H (2003). Understanding Sustainable Architecture. Tayler\& Francis

- Alvarez, S.P.; Lee, K.; Park, J.; Rieh, S.-Y. A (2016) Comparative Study on Sustainability in Architectural Education in Asia-With a focus on professional degree curricula. Sustainability 2016, 8, 290.

- Aslani, R (2001). Sustainable Development Definitions and Prospective. Journal of Housing and Rural Environment (93) 43.

- Baird, G. (2001) The Architectural Expression of Environmental Control system. London and New York: Spon Press.

- Bauman, Z. (1995) Life in Fragments: Essays in postmodern morality. Oxford: Blackwell publishers.

- Bauman, Z. (2005) The individualized society. Cambridge: polity press.

- $\quad$ Brodhag, C., \& Taliere, S. (2006) Sustainable development strategies: Tools for policy coherence. Natural Resources Forum, 136-145.

- Barr, S., Gilg, A., (2006) Sustainable lifestyles: framing environmental action in and around the home. Geoforum 37 (6), 906-920.

- $\quad$ Bonsdrof, Z. (1993) Postmodern Ethic. Oxford: Blackwell publishers.

- Brez, G. (1983) The image: knowledge in life and society Michigan. The University of Michigan press.

- Berbbia, C. A. (2012). Harmonization Between Architecture and Nature: Eco-Architecture. IV.

- Balaram, S. (2011). Thinking Design. SAGEP.

- Edwards, B. (2001). Green Architecture. Wiley.

- Evan, M. (2000). Principles of Environmental and Heritage Law. Prospect Media.

- Forest Steward Ship Council Principles. (1993). www.rainforestinfo.org.au .

- Govorushko, S. (2011). Natural Processes and Human Impacts Interactions Between Humanity and The Environment. Springer. 
- James, V. (2018). Capacity Building for Sustainable Development. CABI.

- Janet, M; Thomas; Scott, J; Callan. (2013). Environmental Economics and Management. Theory, Policy and Applications. Cengage Learning.

- Herfe, F. (1998) Australian Commercial Building Sector greenhouse gas Emissionns 19902010, Canberra: Australian greenhouse Office.

- Jencks, C. (2007). Critical Modernism: What is Post Modernism Going? What is Post Modernism? Wiley.

- Jenks, C. (2002). Visual Culture. Routledge.

- Keitsch, M. (2012) Sustainable Architecture, Design and Housing. Sustainable Development. Volume20, Issue 3, 141-145 May-June 2012.

- Marques, B\& Loureiro, C. (2013). Sustainable Architecture: Practices and Methods to Achieve Sustainability in Construction. IACSIT International Journal of Engineering and Technology, Vol. 5, No. 2, April 2013.

- Maxman, S. (2000). The Practice of Sustainable Development. Washington DC: Urban Land Institute.

- McDonough, W. (2000). The Principles: Design for Sustainability 5Th Ed 1992.

- Nath, B; Hens, L. (2006). The Word Summiton Sustainable Development. Springer Science \& Business Media.

- Pascual L.; Francisco,S. (2015) Sustainable Architecture and Traditional Rural Environmental: Moratalla (MURCIA, SPAIN). International Congress on sustainable construction \& ecoefficient solutions No 2, May 2015.

- Pollington, C; Sebestyen, G. (2007). New Architecture and Technology. Routledge.

- Paul, J. (2006). Looking of The Landscapes Courbet and Modernism. Symposium, Getty Museum.

- Raghab, A and Elhimy, h. (2016) Green Architecture: A Concept of Sustainability. ProcediaSocial and Behavioral Sciences. Volume 216, January 2016.

- Radford, A. Williamson, T. and Bennetts H. (2004) Understanding Sustainable Architecture. Spon Press T. F.G New York. 
- Revedin, J. Hélène, M. Chavannes,C. Revedin, J. (2013) Sustainable Design: Towards a New Ethic in Architecture and Town Planning. Walter de Gruyter.

- Sassi, P. (2006) Strategies for Sustainable Architecture. Taylor \& Francis.

- Steven, A. (2011) Technology and Place: Sustainable Architecture. University of Texas Press.

- Sylvan, R \& Bennett, D. (1994). The Greening of Ethic. White house Press.

- Wong, Y; Siu, K. (2018). Practice and Progress in Social design and Sustainability. IGI Global.

- United Nations. (1992). United Nations Framework Convention on Climate change.

- United Nation on Environment and Development (UNED). (1992). Earth Summit. Rio De Jeneiro, Brazil. 